\title{
Nonlinear observer based PI sliding surface of adaptive sliding mode control for boost converter in PV system
}

\author{
Ramadhani Kurniawan Subroto, Lunde Ardhenta, Eka Maulana \\ Department of Electrical Engineering, Brawijaya University, Indonesia
}

\begin{abstract}
Article Info
Article historys:

Received Mar 27, 2019

Revised May 7, 2019

Accepted May 24, 2019

\section{Keywords:}

Adaptive sliding mode control Boost converter

Nonlinear observer

Photovoltaic system

PI sliding surface

ABSTRACT

In photovoltaic system, solar energy is not able to be directly utilized to the grid. This is because the the generated output voltage from solar array are fluctuating depends on the environmental condition, such as the intensity of solar irradiance and temperature. Any changes from those variables will affect the generated output voltage. Boost converter is one type of power converter that is able to regulate the output voltage of solar array to dc grid. However, the dynamics of boost converter is nonlinear and non-minimum phase. Therefore, it requires an appropriate control method that can force the output voltage follows the desired reference voltage, by considering the fluctuation of environmental conditions and loads. To reduce the number of sensors and cost investment, nonlinear observer technique is employed to estimate the input voltage and load variations. By considering this problem, this paper is aimed at designing nonlinear observer based on adaptive sliding mode control with PI sliding surface for boost converter. The stability of proposed system is investigated through analytical and simulation proof. As comparison with PID controller, the performance of proposed system has produced Integral Absolute Error (IAE) about 7 times smaller than PID controller when it is tested under various conditions.
\end{abstract}

Copyright $(2019$ Institute of Advanced Engineering and Science. All rights reserved.

\section{Corresponding Author:}

Ramadhani Kurniawan Subroto, Department of Electrical Engineering, Brawijaya University, 167 MT Haryono Road, Malang, 65145, Indonesia email: ramasubroto@ub.ac.id

\section{INTRODUCTION}

The research on renewable energy area has become massively developed over the last decades due to the fact that renewable energy provides clean power generation [1-2]. Amongst other renewable energy, solar energy has been intensively developed due to its unlimited availability. However, extracting the energy of photovoltaic system requires power converters as an interface to connect solar array to the grid [3]. In addition, the output voltage of solar array is relatively low. Therefore, power converters, such as boost converter is implemented to rise the output voltage generated from photovoltaic. On the other hand, voltage generated from solar array is affected by the intensity of solar irradiance and temperature. When solar irradiance and temperature vary, the output voltage will be varying [4]. Based on those problems, boost converter is employed to regulate the output voltage produced by photovoltaic. This converter is the fundamental device of DC/DC converter to increase the input voltage level. Eventhough this converter is only composed by a capacitor, an inductor, a resistor, and a MOSFET, this converter has nonlinear characteristics and non-minimum phase which are not an easy task to be controlled. Besides, the intensity of solar irradiance and temperature variations have to be considered for designing the controller in order to obtain the best performance for voltage regulation of this converter.

Various control strategies have been applied to overcome this problem. PID controller has been conducted for regulating the output voltage of boost converter [5-7]. Adaptive control strategy has been 
simulated for boost converter [8]. However, those methods require small signal analysis such that the boost dynamics is linearized under low operating point. As a result, the controller only satisfies certain condition and the stability of overall system cannot meet all operating points.

Due to nonlinear characteristics of boost converter, some researches have employed nonlinear controller such as sliding mode control. The robustness against parameter uncertainty and disturbance are the main reason why sliding mode control is utilized to control nonlinear system, including boost converter. Many sliding mode control methods [9-13] had been applied to boost converter. However, in practical, this control method requires to be fully known some variables, such as input voltage, inductor current, output voltage, and resistance load. As consequences, many sensors are needed to be installed to acquire those variables as input control. Implementing those methods causes increasing cost production and adding more space and weight in real system. Therefore, to reduce the number of sensors, nonlinear disturbance observer [13-15] is designed to estimate some variables, such as inductor current, output voltage, resistance load, and input voltage generated from solar array. The nonlinear disturbance observer accurately generates the estimated value of resistance load and input voltage such that when the variations of those variables exist, the proposed controller is still able to overcome those disturbances. In sliding mode control design, steady state error regulation needs to be considered. However, in [13], it is employed standard sliding surface and only use equivalent control signal to regulate boost converter. This can cause the output voltage response cannot track the varying desired output voltage and leads to steady state error. To enhance system performance, adaptive sliding mode control is applied to the boost converter for overcoming parameter uncertainty and disturbance [16-17]. Steady state error can be eliminated by constructing PI sliding surface, while ensuring sliding mode in finite time is employed reaching law dynamics and incorporates it to natural control signal. Therefore, nonlinear observer based adaptive sliding mode control with PI sliding surface is proposed for boost converter. The main contribution of this paper is to improve the system performance of voltage regulation boost converter using the combination of nonlinear observer and adaptive sliding mode control by modifying the conventional sliding surface into PI structure sliding surface. In addition, the stability of proposed method is proven by using direct Lyapunov method.

The next section discusses about large signal modeling of boost converter and proposed method for controlling and estimating. It also includes the controller and observer stability proof. The research method is described in Section 2. Section 3 is devoted to elaborate result and discussion about the proposed system performance. A conclusion and reference list is in the end of paper.

\section{RESEARCH METHOD}

In this section, the large signal boost converter modeling is derived and proposed method is described. The stability analysis of nonlinear observer is conducted. Its effect, when it is incorporated with the proposed controller, is proved by employing Lyapunov stability theory.

\subsection{Boost Converter Modeling}

The nonlinear model of boost converter is obtained by using Kirchoff current and voltage laws [16, 18]. The model is described in state space representation and is assumed in continuous conduction mode as

$$
\begin{aligned}
& \dot{x}_{1}=-\frac{1}{R C} x_{1}+(1-u) \frac{x_{2}}{C} \\
& \dot{x}_{2}=-(1-u) \frac{x_{1}}{L}+\frac{E}{L}
\end{aligned}
$$

where $x_{1}$ and $x_{2}$ represent the measured / actual output voltage and inductor current, respectively.

The input voltage is represented with $E$. Resistor, capacitor, and inductor are $R, C, L$, respectively. Duty ratio as an input is denoted with $u$.

\subsection{Nonlinear Observer}

The nonlinear observer in this paper is proposed to estimate the value of some variables, such as output voltage $\left(\hat{x}_{1}\right)$, inductor current $\left(\hat{x}_{2}\right)$, input voltage $(\hat{E})$, and resistance load $(\hat{R})$. The nonlinear observer for boost converter is designed as

$$
\begin{aligned}
& \dot{\hat{x}}_{1}=-\frac{1}{\hat{R} C} x_{1}+(1-u) \frac{\hat{x}_{2}}{C}+\eta_{1}\left(x_{1}-\hat{x}_{1}\right) \mathrm{b} \\
& \dot{\hat{x}}_{2}=-(1-u) \frac{\hat{x}_{1}}{L}+\frac{\hat{E}}{L}+\eta_{2}\left(x_{2}-\hat{x}_{2}\right)
\end{aligned}
$$


where $\eta_{1}>0$ and $\eta_{2}>0$ are observer gains, while $\hat{x}_{1}$ and $\hat{x}_{2}$ are the estimates of $x_{1}$ and $x_{2}$, respectively. Let estimation errors are defined as follows: $\tilde{x}_{1}=x_{1}-\hat{x}_{1}, \tilde{x}_{2}=x_{2}-\hat{x}_{2}, \tilde{E}=E-\hat{E}$, and $\tilde{R}=R-\hat{R}$.

Then, the estimator error dynamics is given

$$
\begin{aligned}
& \dot{\tilde{x}}_{1}=-\frac{1}{\tilde{R} C} x_{1}+(1-u) \frac{\tilde{x}_{2}}{C}-\eta_{1} \tilde{x}_{1} \\
& \dot{\tilde{x}}_{2}=-(1-u) \frac{\tilde{x}_{1}}{L}+\frac{\tilde{E}}{L}-\eta_{2} \tilde{x}_{2}
\end{aligned}
$$

\subsection{Proposed Controller}

The proposed controller in this paper is adaptive sliding mode control. The "adaptive" term refers to the parameters of controller which are adjusted such that can cope any parameter variations or uncertainties. In order to obtain proposed controller, it is required to determine these steps:

Step 1: Determine the PI sliding surface

Step 2: Determine the reaching dynamics law. In many literatures, reaching dynamics is employed to satisfy the reachability condition, where the trajectory starts from any initial condition into its sliding surface in finite time

Step 3: Derive and obtain the control signal from time derivative of sliding surface and reaching dynamics law

The basic concept of sliding mode control design is by determining the sliding surface and obtaining control signal. In this paper, PI structure of sliding surface is used as

$$
\sigma=\hat{x}_{2}-I_{\text {Lref }}+\lambda \int\left(\hat{x}_{2}-I_{\text {Lref }}\right) d t
$$

where $I_{\text {Lref }}$ is desired inductor current, later defined in (6), and $\lambda$ is control parameter whose value is positive definite.

Reaching law dynamics is constructed to ensure sliding mode in finite time as

$$
\dot{\sigma}=-\rho \sigma-\omega \operatorname{sgn}(\sigma)
$$

Estimated desired inductor current is defined as

$$
I_{\text {Lref }}=\frac{V_{r e f}^{2}}{\widehat{R} \hat{E}}
$$

where $V_{\text {ref }}$ is desired output voltage.

An error between estimated inductor current and its reference is defined as

$$
e=\hat{x}_{2}-I_{\text {Lref }}
$$

\subsection{Stability Analysis}

Stability analysis is conducted to analyze the stability of overall system. Lyapunov stability method is employed since the characteristics of the system is nonlinear. Adaptive mechanism for nonlinear observer is determined based on Lyapunov method. In addition, to ensure in sliding mode condition during finite time, reaching laws dynamics is added to the controller design procedure. Thus, the overall system is checked by using Lyapunov direct method.

\section{Theorem 1:}

Considering the system (1) with observer (2) and sliding surface given (4), the control error $e$ defined by (7) satisfies $\lim _{t \rightarrow \infty} e(t)=0$ and $\tilde{x}_{1}, \tilde{x}_{2} \rightarrow 0, \hat{E} \rightarrow E, \hat{R} \rightarrow R$ asymptotically, if the control law is given by

$$
u=1-\left[\frac{\hat{E}+\eta_{2} L \tilde{x}_{2}+\frac{\gamma_{1} L V_{r e f}^{2}}{\hat{E}} x_{1} \tilde{x}_{1}+\frac{\gamma_{2} L V_{r e f}^{2}}{\hat{R} \widehat{E}^{2}} \tilde{x}_{2}+\lambda L\left(\hat{x}_{2}-\frac{V_{r e f}^{2}}{\hat{R} \hat{E}}\right)+L \rho \sigma+L \omega \operatorname{sgn}(\sigma)}{\hat{x}_{1}}\right]
$$

where sgn( ) represents signum function. Control parameters are chosen such that $\rho>0, \gamma_{1}>0, \gamma_{2}>$ $0, \omega>0$ and estimated parameters are tuned by using adaptive mechanism

Nonlinear observer based PI sliding surface of adaptive sliding mode ... (Ramadhani Kurniawan Subroto) 


$$
\begin{aligned}
& \dot{\hat{\theta}}=(1 / \dot{\hat{R}})=-\gamma_{1} x_{1} \tilde{x}_{1} \\
& \dot{\hat{E}}=\gamma_{2} \tilde{x}_{2}
\end{aligned}
$$

Proof: Selecting positive definite Lyapunov function as

$$
V=\frac{1}{2} C \tilde{x}_{1}^{2}+\frac{1}{2} L \tilde{x}_{2}^{2}+\frac{1}{2 \gamma_{1}} \tilde{\theta}^{2}+\frac{1}{2 \gamma_{2}} \tilde{E}^{2}
$$

where $\gamma_{1}$ and $\gamma_{2}$ are selected to be positive definite. Then, by taking time derivative of Lyapunov function (11), it is obtained

$$
\dot{V}=C \tilde{x}_{2} \dot{\tilde{x}}_{2}+L \tilde{x}_{1} \dot{\tilde{x}}_{1}+\frac{1}{\gamma_{1}} \tilde{\theta} \dot{\tilde{\theta}}+\frac{1}{\gamma_{2}} \tilde{E} \tilde{\tilde{E}}
$$

By substituting (3) into (12), it is obtained

$$
\dot{V}=-\eta_{1} C \tilde{x}_{1}^{2}-\eta_{2} L \tilde{x}_{2}^{2}-\tilde{\theta}\left[x_{1} \tilde{x}_{1}+\frac{1}{\gamma_{1}} \dot{\hat{\theta}}\right]-\tilde{E}\left(\frac{1}{\gamma_{2}} \dot{\hat{E}}-\tilde{x}_{2}\right)
$$

To achive asymptotically stable, equation in the bracket should be zero. Therefore, it is obtained

$$
\begin{aligned}
& \dot{\hat{\theta}}=-\gamma_{1} x_{1} \tilde{x}_{1} \\
& \dot{\hat{E}}=\gamma_{2} \tilde{x}_{2}
\end{aligned}
$$

Thus, by substituting (14) and (15) into (13), we can have

$$
\dot{V}=-\eta C \tilde{x}_{1}^{2}-\eta_{2} L \tilde{x}_{2}^{2}
$$

Since (16) is negative definite, it can be concluded that $\tilde{x}_{1}, \tilde{x}_{2}, \tilde{\theta}, \tilde{E} \rightarrow 0$ asymptotically.

Lemma 1: The reaching dynamics (5) for $\rho$ and $\omega>0$ guarantees that reachability condition

$$
\sigma \cdot \dot{\sigma}<-\Gamma|\sigma|
$$

is achieved for some $\Gamma>0$

Proof: Equating time derivative of sliding surface (4) into reaching laws dynamics (5), the formula can be generalized as follows

$$
\dot{\sigma}=\dot{\hat{x}}_{2}-\frac{V_{r e f}^{2}}{\hat{E}} \hat{\theta} \dot{\hat{\theta}}+\frac{V_{r e f}^{2}}{\hat{E}^{2}} \hat{\theta} \dot{\hat{E}}+\lambda\left(\hat{x}_{2}-I_{\text {Lref }}\right)=-\rho \sigma-\omega \operatorname{sgn}(\sigma)
$$

By substituting (2), (14), and (15) into (18), it is obtained the control signal

$$
u=1-\left[\frac{\hat{E}+\eta_{2} L \tilde{x}_{2}+\frac{\gamma_{1} L V_{r e f}^{2}}{\widehat{E}} x_{1} \tilde{x}_{1}+\frac{\gamma_{2} L V_{r e f}^{2}}{\widehat{R} \widehat{E}^{2}} \tilde{x}_{2}+\lambda L\left(\hat{x}_{2}-\frac{V_{r e f}^{2}}{\widehat{R} \hat{E}}\right)+L \rho \sigma+L \omega \operatorname{sgn}(\sigma)}{\hat{x}_{1}}\right]
$$

Then, the reachability condition can be achieved by selecting positive definite Lyapunov function

$$
V=\frac{1}{2} \sigma^{2}>0
$$

By taking time derivative of (20), it is obtained

$$
\dot{V}=\sigma \dot{\sigma}=\sigma(-\rho \sigma-\omega \operatorname{sgn}(\sigma)) \leq-\Gamma|\sigma|
$$

where $\Gamma \geq \rho|\sigma|+\omega$. Thus, it completes the proof. 
Lemma 2: During sliding mode, at steady state condition, the control law becomes

$$
u=1-\frac{E}{x_{1}}=d
$$

where $d$ is the steady state duty ratio. Therefore, this ensures that the value of output voltage can follow the reference voltage.

Proof: At sliding mode $\sigma=0$, it satisfies that the estimator error $\tilde{x}_{1} \rightarrow 0$ and $\tilde{x}_{2} \rightarrow 0$ and estimated value of $\hat{E} \rightarrow E, \hat{x}_{1} \rightarrow x_{1}, \hat{x}_{2} \rightarrow x_{2}, \hat{R} \rightarrow R$, and control error $e \rightarrow 0$. Thus, by considering those conditions at sliding mode, (19) can be obtained

$$
u=1-\frac{E}{x_{1}}
$$

which is duty ratio $d$ of the boost converter. It completes the proof of stability of control signal.

To determine reference voltage, it is employed model reference to achieve transient dynamics and reduce a sharp voltage command as

$$
\dot{V}_{\text {ref }}=w_{d}\left(V_{c m d}-V_{\text {ref }}\right)
$$

where $V_{c m d}$ is the command dc output voltage and $w_{d}$ is constant represent transient dynamics of reference voltage.

\subsection{System Testing}

The block diagram of proposed system is illustrated in Figure 1 and system parameters is described in Table 1. The system parameters consist of boost converter, nonlinear observer, controller, and reference model parameter. Boost converter parameters are calculated based on continuous conduction mode $(\mathrm{CCM})$. The method to select boost converter parameters can be found in [18]. The selection of nonlinear observer parameters are based on (11) and (16). Eq. (11) mentioned that Lyapunov function has to be positive definite, thus adaptive law gains are selected to be positive definite. Eq. (16) are obtained to be negative definite, thus in order to ensure (16) to be negative definite, the observer gains has to be selected into positive definite. Therefore, in Table 1, adaptive law gains and observer gains are selected to be positive definite. The selection of proposed controller paramaters follows (4) and (21). The photovoltaic rating is provided in Table 2 . The polycrystalline solar panel is used for this paper. The numerical simulation is conducted to prove the effectiveness of the proposed method. The system will be tested under six scenarios, which in detail will be described in Section 3.

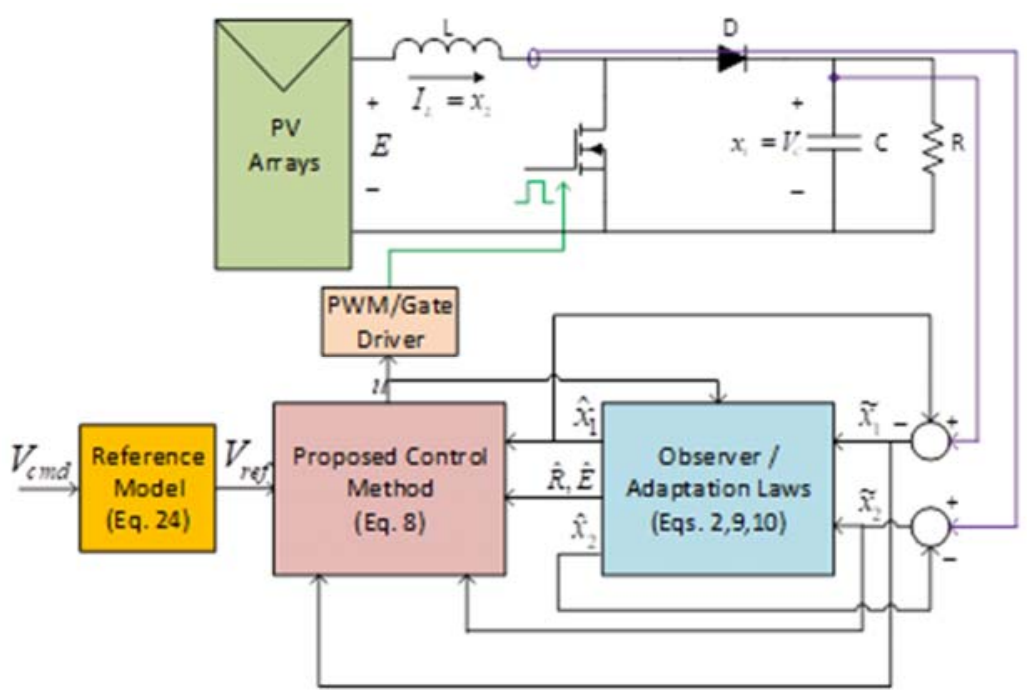

Figure 1. Block diagram of proposed method

Nonlinear observer based PI sliding surface of adaptive sliding mode ... (Ramadhani Kurniawan Subroto) 


\begin{tabular}{ccccc}
\multicolumn{5}{c}{ Table 1. Proposed system parameters } \\
\hline System & Parameter & Symbol & Value & Units \\
\hline \multirow{3}{*}{ Boost converter } & Inductance & $L$ & 4.7 & $\mathrm{mH}$ \\
& Capacitance & $C$ & 47 & $\mu \mathrm{F}$ \\
& Resistor load & $R$ & $100-200$ & $\Omega$ \\
& Input DC voltage & $E$ & $12-18$ & $\mathrm{~V}$ \\
Observer & Observer gains & $\eta_{1}$ & $10^{4}$ & - \\
& & $\eta_{2}$ & $10^{4}$ & - \\
& Adaptation law gains & $\gamma_{1}$ & $10^{4}$ & - \\
Controller & Controller parameter & $\gamma_{2}$ & 1 & - \\
& Reaching law dynamics & $\rho$ & $10^{4}$ & - \\
Reference Model & Transient constant & $\omega$ & 0.1 & - \\
& & $\omega_{d}$ & $10^{-2}$ & - \\
\hline
\end{tabular}

Table 2. Photovoltaic rating

\begin{tabular}{ccc}
\hline Parameter & Value & Units \\
\hline Maximum voltage $\left(\mathrm{V}_{\mathrm{mp}}\right)$ & 17.6 & $\mathrm{~V}$ \\
Maximum current $\left(\mathrm{I}_{\mathrm{mp}}\right)$ & 5.69 & $\mathrm{~A}$ \\
Open circuit voltage $\left(\mathrm{V}_{\mathrm{OC}}\right)$ & 22.6 & $\mathrm{~V}$ \\
Short circuit current $\left(\mathrm{I}_{\mathrm{sC}}\right)$ & 6.09 & $\mathrm{~A}$ \\
Maximum power at STC $\left(\mathrm{P}_{\max }\right)$ & 100 & $\mathrm{~W}$ \\
\hline
\end{tabular}

\section{RESULTS AND DISCUSSION}

Numerical simulation is conducted to test the effectiveness of the proposed system. Test simulation is set to be 0.9 seconds. Two different controllers, which are PID controller and observer based sliding mode with conventional sliding surface [13], are employed to be compared with proposed method. The PID controller parameters are determined by using direct synthesis method. According to the calculation, the PID controller parameters are obtained and presented in Table 3. The difference of our proposed method with [13] are sliding surface structure and reaching law dynamics. In [13], the sliding surface is merely using state of inductor current error, while our proposed method is using PI structure for its surface. Reaching law dynamics in [13] is not utilized, while it is employed in our proposed method. The parameters of [13] are based on Table 1, but there are no reaching law dynamics parameters and $\lambda$ defines the gain of inductor current error. The test scenarios conducted for system testing are illustrated in Table 4. There are six scenarios for this system testing, includes input voltage, resistance load, and reference voltage variations.

Table 3. PID Controller Parameter

\begin{tabular}{lcc}
\hline \multicolumn{1}{c}{ Parameter } & Symbol & Value \\
\hline Proportional Constant & $K_{P}$ & $5.17 \times 10^{-4}$ \\
Integral Constant & $K_{I}$ & 2.08 \\
Derivative Constant & $K_{D}$ & $2.36 \times 10^{-6}$ \\
\hline
\end{tabular}

Table 4. System Testing Scenario

\begin{tabular}{ccccccc}
\hline & Scenario 1 & Scenario 2 & Scenario 3 & Scenario 4 & Scenario 5 & Scenario 6 \\
\hline Simulation time (s) & $0-0.15$ & $0.15-0.3$ & $0.3-0.45$ & $0.45-0.6$ & $0.6-0.75$ & $0.75-0.9$ \\
Reference voltage (V) & 24 & 24 & 24 & 36 & 36 & 36 \\
Input voltage (V) & 12 & 18 & 18 & 18 & 12 & 12 \\
Resistance load $(\Omega)$ & 100 & 100 & 200 & 200 & 200 & 100 \\
\hline
\end{tabular}

The output voltage response based on conducted test scenarios is depicted in Figure 2. It can be seen that the proposed method can cope the input voltage and load variations by producing the fast recovery time and smaller voltage deviation compared to PID controller and the controller that proposed in [13]. The performance analysis of both systems are measured by using Integral Absolute Error (IAE) shown and summarized in Table 5. The lowest IAE indicates that the system shows better performance. According to the calculation, the proposed system has produces IAE 2 times smaller than system with controller proposed in [13]. Moreover, it generates almost 7 times smaller than system with PID controller. In Table 5, $\Delta \mathrm{V}$ represents the voltage deviation, while $t_{s}$ and $t_{\text {rec }}$ represent settling time and recovery time, respectively. Voltage deviation is defined as the difference between maximum actual voltage and reference voltage.

Indo. J. Elec. Eng. \& Inf, Vol.7, No. 2, June 2019: 211 - 220 
Both proposed method and PID controller prove the ability to track the desired voltage. It has been shown in Table 5 that during reference changes, the proposed method has fast transient response since it only needs $17.7 \mathrm{~ms}$ to reach steady state, while PID controller is only able to reach steady in $28.4 \mathrm{~ms}$. When the disturbances are applied in the system, the PID controller is not robust enough to overcome them. It can be indicated that PID controller has higher voltage deviation and slower recovery time than our proposed method. Figure 3 depicts the output voltage response during condition 1 to 3, while Figure 4 depicts the output voltage response during scenario 4 to 6 . The proposed method is able to overcome any sudden input voltage and load variations, while PID controller experiences high oscillations and slow recovery time when input voltage is decreased $50 \%$ from its nominal value.

Both PID controller and our proposed method have has successfully eliminated steady state error. It can be depicted by Figure 5. However, adaptive sliding mode in Ref [13] is not able to eliminate steady state error in every scenario. The summary of steady state error performance of all controllers is presented in Table 6. The highest steady state error in Ref [13] happened when the resistance load is increased.

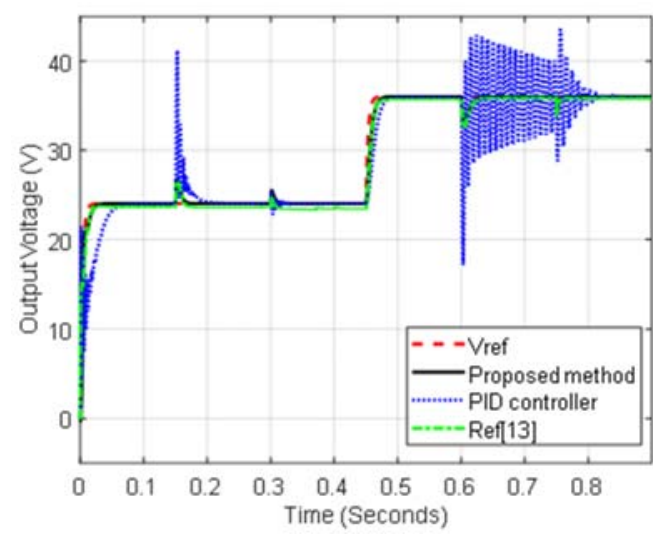

Figure 2. Output voltage response

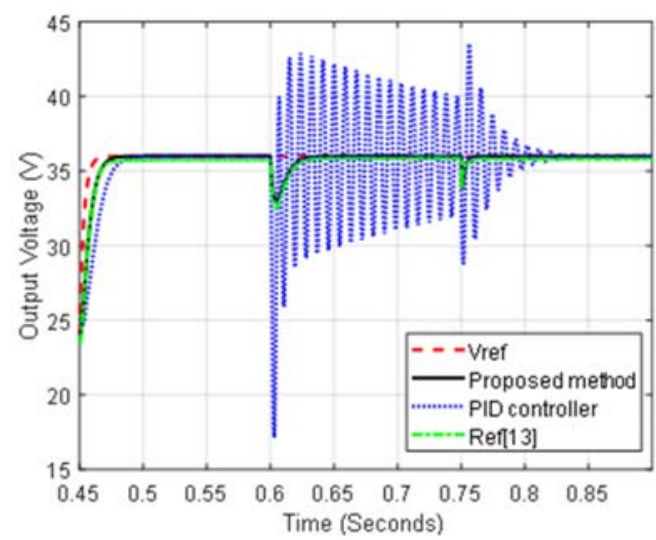

Figure 4. Output voltage response during scenario 4 to 6

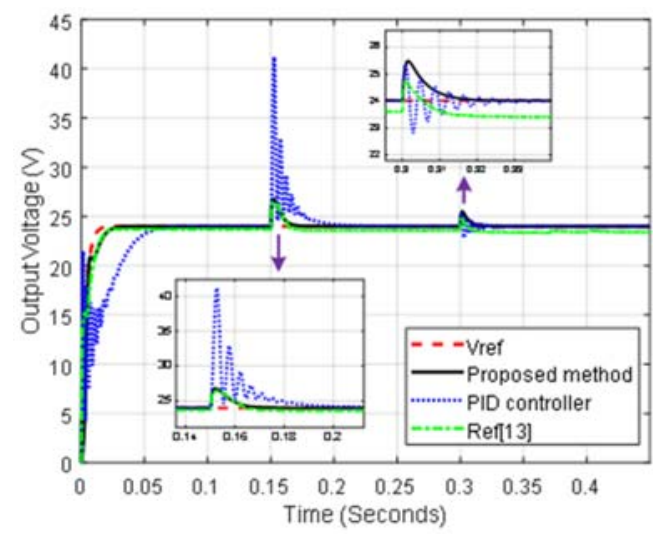

Figure 3. Output voltage response during scenario 1 to 3

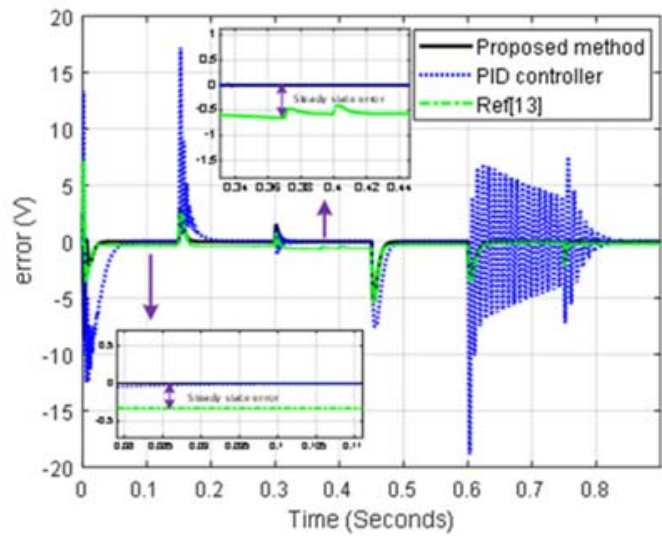

Figure 5. Steady state error response

Table 5. Comparison of IAE, overshoot, and recovery time results

\begin{tabular}{|c|c|c|c|c|c|c|c|c|c|c|c|c|c|}
\hline & \multirow[b]{2}{*}{ IAE } & \multicolumn{2}{|c|}{ Scenario 1} & \multicolumn{2}{|c|}{ Scenario 2} & \multicolumn{2}{|c|}{ Scenario 3} & \multicolumn{2}{|c|}{ Scenario 4} & \multicolumn{2}{|c|}{ Scenario 5} & \multicolumn{2}{|c|}{ Scenario 6} \\
\hline & & $\begin{array}{l}\Delta \mathrm{V} \\
(\mathrm{V})\end{array}$ & $\begin{array}{c}\mathrm{t}_{\mathrm{s}} \\
(\mathrm{ms})\end{array}$ & $\begin{array}{l}\Delta \mathrm{V} \\
(\mathrm{V})\end{array}$ & $\begin{array}{l}\text { trec } \\
(\mathrm{ms})\end{array}$ & $\begin{array}{l}\Delta \mathrm{V} \\
(\mathrm{V})\end{array}$ & $\begin{array}{c}\text { trec } \\
(\mathrm{ms})\end{array}$ & $\begin{array}{l}\Delta \mathrm{V} \\
(\mathrm{V})\end{array}$ & $\begin{array}{c}\mathrm{t}_{\mathrm{s}} \\
(\mathrm{ms})\end{array}$ & $\begin{array}{l}\Delta \mathrm{V} \\
(\mathrm{V})\end{array}$ & $\begin{array}{c}\mathrm{t}_{\mathrm{rec}} \\
(\mathrm{ms})\end{array}$ & $\begin{array}{l}\Delta \mathrm{V} \\
(\mathrm{V})\end{array}$ & $\begin{array}{c}\mathrm{t}_{\mathrm{rec}} \\
(\mathrm{ms})\end{array}$ \\
\hline $\begin{array}{l}\text { Proposed } \\
\text { Method }\end{array}$ & 0.177 & 0 & 15.48 & 2.7 & 12.2 & 1.47 & 3.7 & 0 & 17.7 & 2.99 & 17.7 & 1.56 & 3.6 \\
\hline $\begin{array}{l}\text { PID controller } \\
\text { Ref [13] }\end{array}$ & $\begin{array}{l}1.227 \\
0.323\end{array}$ & $\begin{array}{l}0 \\
0\end{array}$ & $\begin{array}{l}55.21 \\
20.92\end{array}$ & $\begin{array}{l}17.2 \\
2.9\end{array}$ & $\begin{array}{l}38 \\
14\end{array}$ & $\begin{array}{l}1.38 \\
1.16\end{array}$ & $\begin{array}{l}10.7 \\
7.1\end{array}$ & $\begin{array}{l}0 \\
0\end{array}$ & $\begin{array}{l}28.4 \\
18.7\end{array}$ & $\begin{array}{c}18.86 \\
3.19\end{array}$ & $\begin{array}{c}562 \\
19.1\end{array}$ & $\begin{array}{l}2.74 \\
2.04\end{array}$ & $\begin{array}{l}13.2 \\
3.4\end{array}$ \\
\hline
\end{tabular}

Nonlinear observer based PI sliding surface of adaptive sliding mode ... (Ramadhani Kurniawan Subroto) 
Table 6. Comparison of steady state error results

\begin{tabular}{ccccccc}
\hline & Scenario 1 & Scenario 2 & Scenario 3 & Scenario 4 & Scenario 5 & Scenario 6 \\
\cline { 2 - 7 } & $\%$ Ess (\%) & \%Ess (\%) & \%Ess (\%) & \%Ess (\%) & \%Ess (\%) & $\%$ Ess (\%) \\
Proposed Method & 0 & 0 & 0 & 0 & 0 & 0 \\
PID controller & 0 & 0 & 0 & 0 & 0 & 0 \\
Ref [13] & 1.42 & 1.83 & 2.5 & 0.86 & 0.44 & 0.58 \\
\hline
\end{tabular}

The estimated input voltage and load resistance are shown in Figure 6. The initial condition of load resistor estimation is $20 \Omega$, while input voltage is $30 \mathrm{~V}$. Load resistor estimation can reach the actual value from initial condition in $19.54 \mathrm{~ms}$, while the input voltage estimation can follow its actual value from initial condition in $21.24 \mathrm{~ms}$. It clearly shows that proposed method is able to follow the actual value of those variables. Moreover, it indicates that nonlinear observer is very effective to estimate those disturbances. The state trajectory is shown in Figure 7. According to that figure, it can be pointed out that the state trajectory can reach equilibrium from its initial condition in finite time.
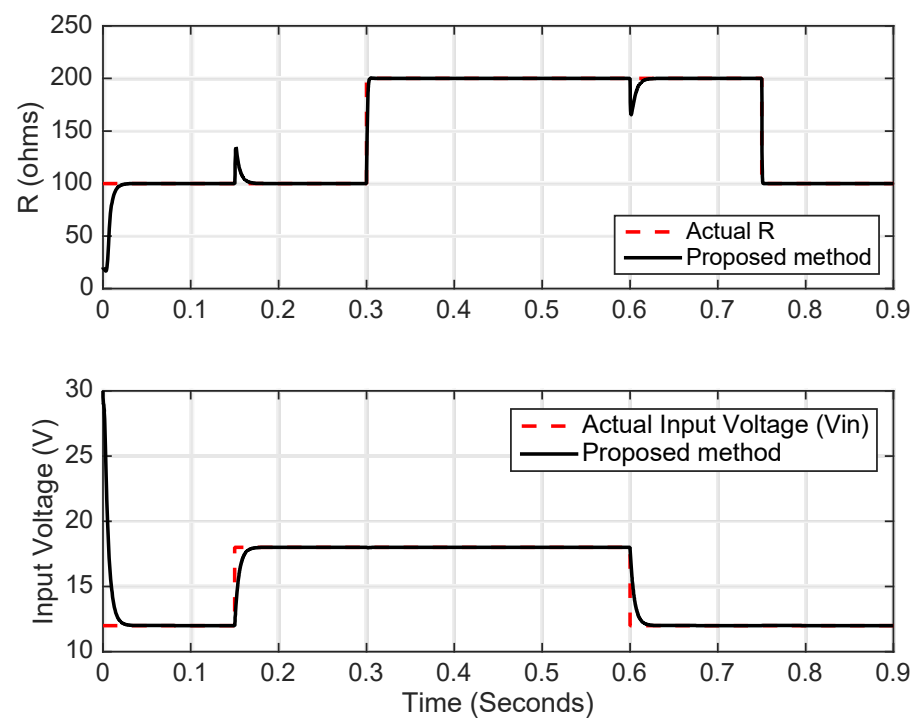

Figure 6. Load resistance (top) and input voltage (bottom) response

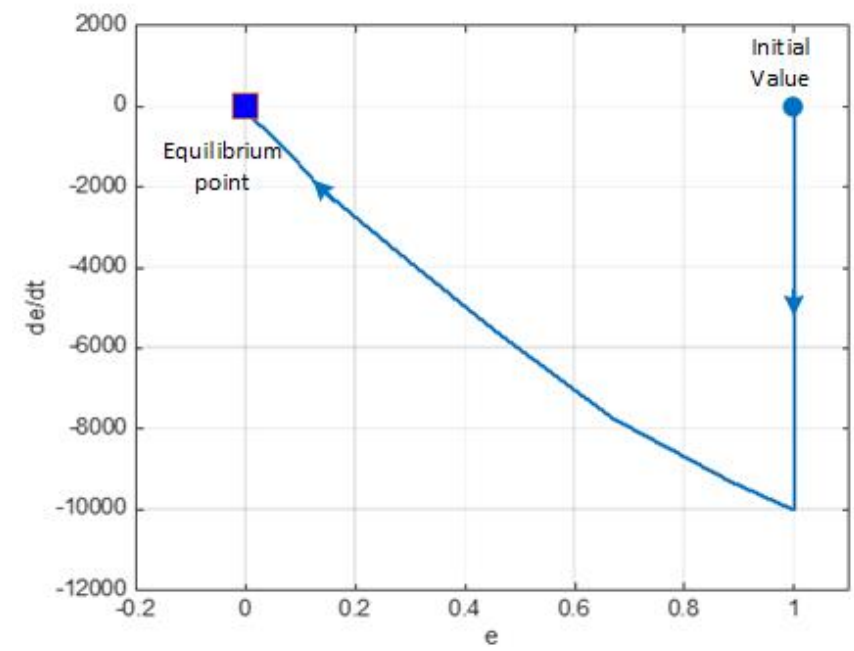

Figure 7. State trajectory of proposed method 


\section{CONCLUSION}

According to the analytical and simulation proof, the proposed system shows its robustness and stability against the disturbances. As summarized in Table 5, the IAE of proposed method is 7 times smaller than PID controller and 2 times smaller than adaptive sliding mode with conventional sliding surface. It indicates that the output response can follow perfectly the desired reference. Moreover, the proposed method is able to eliminate steady state error in all conditions, while adaptive sliding mode with conventional sliding surface is not able to eliminate it. The proposed system also shows fast transient response, can eliminate steady state error, and has fast recovery time. In addition, the stability analysis of both controller and observer has successfully proven in this paper. It is proven that the estimation error converges to zero and estimated value can accurately estimate the actual value.

\section{ACKNOWLEDGMENTS}

The authors would like to express the gratitude for research funding given by Lembaga Penelitian dan Pengabdian Kepada Masyarakat Universitas Brawijaya (LPPM - UB) through Hibah Penelitian Pemula 2019

\section{REFERENCES}

[1] R.K. Subroto, K.L. Lian, "Modeling of a Multilevel Voltage Source Converter using the Fast Time-Domain Method," IEEE Journal of Emerging and Selected Topics in Power Electronics. vol. 2, no. 4, pp. 1117-1126, 2014

[2] R.K. Subroto, et al., "Modeling of a multilevel voltage source converter using the fast time-domain method," 2018 $18^{\text {th }}$ International Conference on Harmonics and Quality of Power, pp. 1-5, 2018

[3] R.K. Subroto, S.N. Sari, Z. Abidin, K.L. Lian, "Voltage Regulation of Boost Converter using Observer Based Sliding Mode Controller," Telkomnika, vol. 16, no. 6, pp. 2896 - 2904, 2018

[4] L. Ardhenta, et al., "Adaptive Control for Buck Converter in Hybrid Power System based on DMRAC Method," 2018 Electrical Power, Electronics, Communications, Controls and Informatics Seminar (EECCIS), 2018, pp. 282 - 286

[5] Y.I. Son, I.H. Kim, “Complementary PID controller to passivity based nonlinear control for a boost converter," IEEE Transactions of Control System Technology, vol. 20, no. 3, pp. 826 - 834, 2012

[6] J.S. Moreno, et al., "Performance comparison between $\mathrm{H} \infty$ and PID control strategies applied to Boost power converters," 2010 IEEE ANDESCON, pp. 1-6, 2010

[7] G. Abbas, et al., "Set-point tracking of a dc-dc boost converter through optimized PID controllers", 2016 IEEE Canadian Conference on Electrical and Computer Engineering (CCECE), pp. 1 - 5, 2016

[8] M.K.C. Cunha, et al., "Self-tuning adaptive controller applied to boost converter voltage control," 2015 IEEE 13th Brazilian Power Electronics Conference and 1st Southern Power Electronics Conference (COBEP/SPEC), pp. 1-6, 2015

[9] Y.P. Jiao, et al., "An Improved Sliding Mode Controller for Boost Converter in Solar Energy System," 4th IEEE Conference on Industrial Electronics and Applications (ICIEA) 2009, pp. 805-810, 2009

[10] S. Singh, D. Fulwani, V. Kumar, "Robust sliding - mode control of dc/dc boost converter feeding a constant power load," IET Power Electronics, vol. 8, no. 7, pp. 1230-1237, 2015

[11] J. Zhang, et al., "A novel sliding mode controller for dc-dc boost converters under input/load variations," IECON 2015 - 41st Annual Conference of the IEEE Industrial Electronics Society, pp. 1698-1703, 2015

[12] Y. He, et al., "Sliding-mode control for dc-dc converters with constant switching frequency," IEE Proceedings Control Theory and Applications, vol. 153, no. 1, pp. 37-45, 2006

[13] S. Oucheriah, L. Guo, "PWM-based adaptive sliding mode control for boost DC/DC converters," IEEE Transactions on Industrial Electronics, vol. 60, no. 8, pp. 3291-3294, 2013

[14] W. He, et al., "Incremental passivity based control for DC-DC boost converter with circuit parameter perturbations using nonlinear disturbance observer," IECON 2016 - 42 $2^{\text {nd }}$ Annual Conference of the IEEE Industrial Electronics Society, pp. $1353-1358,2016$

[15] R.K. Subroto, et al., "Lyapunov based Estimator for Buck Converter," 2018 Electrical Power, Electronics, Communications, Controls and Informatics Seminar (EECCIS), 2018, pp. $287-292$

[16] R.K. Subroto, et al., "A Novel of Adaptive Sliding Mode Controller with Observer for DC/DC Boost Converters in Photovoltaic System," 2017 5th International Conference on Electrical, Electronics, and Information Engineering, pp. 9-14, 2017.

[17] R.K. Subroto. "Vehicle stability control of 4WD electric vehicle using combined adaptive sliding mode controller and control allocation method," 2017 IEEE 3rd International Future Energy Electronics Conference and ECCE Asia (IFEEC 2017 - ECCE Asia), pp. 812-817, 2017.

[18] D. W. Hart, Power Electronics, 1st ed. New York, NY: McGraw-Hill, 2010. 


\section{BIOGRAPHY OF AUTHORS}

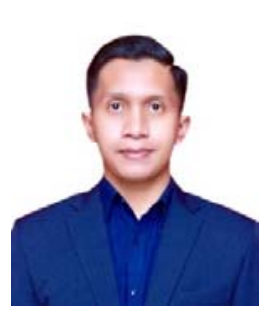

Ramadhani Kurniawan Subroto received B. Eng (2012), M. Eng (2014), and M. Sc (2014) degrees in electrical engineering from Sepuluh Nopember Institute of Technology, Indonesia and National Taiwan University of Science and Technology, Taiwan, respectively. Currently, he works as a Lecturer in Department of Electrical Engineering, Brawijaya University, Indonesia. His main research interest includes control of power electronics, nonlinear control, sliding mode control, observer design, harmonics analysis, and harmonics modeling of power converters.

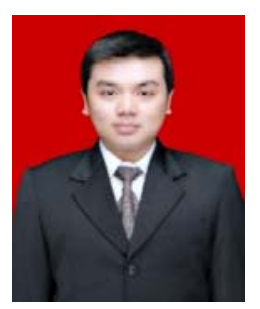

Lunde Ardhenta was born in East Java Province, Indonesia, in 1988. He is currently a junior lecturer at Department of Electrical Engineering, University of Brawijaya, Indonesia. He received the M.S. degree in Department of Electrical Engineering, National ChiaYi University, Taiwan in 2015. He completed his Bachelor degree in Department of Electrical Engineering, University of Brawijaya, Indonesia in 2011. His research interests include renewable energy applications, linear control and digitalized control techniques, and power electronics.

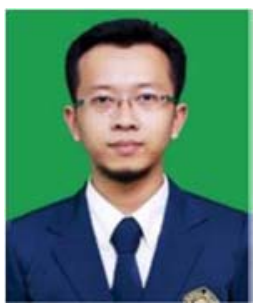

Eka Maulana received B. Eng degree in Electrical Engineering from Brawijaya University, Indonesia in 2009. He completed his M. Eng degree in Electrical Engineering from Miyazaki University in 2011. Currently, he is with the Department of Electrical Engineering, Brawijaya University as a Lecturer. His research interests are in fields of electronics, power electronics, smart grid, renewable energy and energy harvesting devices, molecular electronics, sensors and photonic applications. His affiliations are member of IEEE, PSeeM-RG (Power System Engineering and Energy Management Research Group) and CRC - ASMAT (Collaborative Research Center for Advanced System and Material Technology) Brawijaya University. 